\title{
Optimizing the benefit of multiple sclerosis therapy: the importance of treatment adherence
}

\author{
This article was published in the following Dove Press journal: \\ Patient Preference and Adherence \\ 30 December 2009 \\ Number of times this article has been viewed
}

\section{Francesco Patti \\ Department of Neurology, University of Catania, Catania, Italy}

\begin{abstract}
Poor treatment adherence is problematic in many therapy areas, including multiple sclerosis (MS). Several immunomodulatory drugs are available for the treatment of MS, all of which require frequent parenteral administration. Current first-line therapies are two formulations of interferon (IFN) beta-1a, one of IFN beta-1b, and one of glatiramer acetate. Discontinuation of treatment is common, particularly in the first few months after initiation. Although the true effect of poor adherence to MS therapy is not known, it is likely to lead to a fall in treatment efficacy. Many factors influence a patient's adherence to treatment, including the patient's MS subtype and disability level, cognitive impairment resulting from MS, perceived lack of efficacy of the prescribed medication, and adverse events associated with MS therapy. This article summarizes the barriers to adherence to MS therapies, and discusses patient management strategies that can be employed to encourage adherence. Future advances in the field of MS treatment will be explored, including the development of orally administered drugs, which may enhance adherence.
\end{abstract}

Keywords: multiple sclerosis, adherence, compliance, interruption, adverse events, efficacy, tolerability, management

\section{Introduction}

The World Health Organization (WHO) defines adherence as "The extent to which a person's behavior - taking medication, following a diet, and/or executing lifestyle changes, corresponds with agreed recommendations from a health care provider." Adherence to treatment regimes is essential to ensure patients receive the maximum benefit from their treatment and also to make sure that treatment is cost-effective. Nonadherence or poor adherence to therapy can lead to poor outcomes or treatment failure, and to increased costs. ${ }^{1}$

The WHO considers poor adherence to medication to be a serious problem worldwide. In developed countries, adherence among patients suffering from chronic diseases is as low as $50 \%$. This figure is probably even lower in developing countries. ${ }^{1}$ For example, adherence to oral anticancer agents can be as low as $20 \%,{ }^{2}$ and adherence to some oral treatments for diabetes is only $36 \% .^{3}$

This article will explore the issue of adherence to treatment for multiple sclerosis (MS). The barriers to full adherence encountered by patients and clinicians will be described, and strategies that may be used to improve rates of adherence will be discussed.

\section{Adherence to MS therapy}

MS is a chronic demyelinating autoimmune disorder of the central nervous system. It is estimated to affect 2.5 million people worldwide, and is the most common submit your manuscript $\mid$ www.dovepress.com

Dovepress 
cause of neurological disability among young people. ${ }^{4} \mathrm{MS}$ has several clinical forms. Patients are most often initially diagnosed with relapsing-remitting MS with new symptoms appearing during discrete acute attacks (relapses) between which the patient regains some or all neurological function, although residual disability tends to accumulate over time. Many patients with relapsing-remitting MS go on to develop secondary progressive MS, which is characterized by progressive neurological decline, over which acute relapses may be superimposed. ${ }^{5}$

MS is currently incurable, although a variety of treatment approaches are available, including physiotherapy, psychotherapy, and management strategies to mitigate the symptoms of MS. Immunomodulatory agents are available that can modify the course of the disease by altering the pathological immune responses underlying MS. Treatment with these disease-modifying drugs (DMDs) aims to reduce the rate of acute neurological attacks, and can delay disability progression. First-line treatment options for MS currently consist of four immunomodulatory drugs: interferon (IFN) beta-1a, administered subcutaneously (sc) 3 times weekly; IFN beta-1a, administered intramuscularly (im) once weekly; IFN beta-1b administered sc every other day; and glatiramer acetate administered sc once daily. All of these drugs have to be administered parenterally on a regular basis, and are associated with injection-related side-effects such as injection-site reactions, which may influence adherence, particularly during the first few months of treatment. The second line of treatment for MS includes immunosuppressant agents such as cyclophosphamide and mitoxantrone. While these agents have been shown to be effective in MS therapy, they have widespread effects on the immune system and suppress both beneficial and harmful immune responses. ${ }^{6}$ These drugs tend to be used only in patients who do not respond to first-line therapy, and potential toxicity issues make them a short-term option. Natalizumab is a newer immunosuppressant, which has a more targeted activity against pathological immune responses. Again, because of the potential for serious side-effects, natalizumab is generally only recommended for patients with highly active MS who show an inadequate response to first-line therapy. ${ }^{\text {? }}$

Studies of adherence to MS therapy in clinical practice have shown that patients are most likely to discontinue therapy within the first 6 months after treatment initiation. Discontinuation rates during the first 6 months of treatment have been reported to range from $9 \%$ to $20 \%,{ }^{8,9}$ although abandonment of an MS treatment regimen can happen at any time. In one study of patients with relapsing-remitting MS, with a mean follow-up duration of 4.2 years, $46 \%$ of patients stopped treatment over the course of the study. ${ }^{10}$

Rates of discontinuation of therapy in clinical trials tend to be somewhat lower than in clinical practice, perhaps reflecting the fact that patients enrolled in trials receive more thorough follow up than is usual in everyday practice. ${ }^{8}$ In general, clinical trials of DMDs in MS show favorable rates of adherence, particularly the more recent trials, which routinely employ management strategies to minimize adverse events (AEs) and to ensure patients' compliance with treatment. However, dropout rates from clinical trials may not give an accurate picture of long-term adherence to therapy in the clinical setting, where the patient and physician may elect to change to a different drug, or the patient may choose to discontinue therapy altogether. Additionally, disease management strategies employed as standard practice vary between clinics, and this may cause adherence rates to differ between centers.

\section{Barriers to adherence to MS treatment Disease-related factors}

A patient's subtype of MS may influence their likelihood of adherence to therapy. One study, which followed 632 patients for a mean period of 47.1 months, found that adherence was poorer in patients with secondary progressive MS than in those with relapsing-remitting MS. The authors also noted that the patients with relapsing-remitting MS who stopped therapy were younger than those who remained on treatment, had higher levels of initial disability and more active disease, and were more likely to be female. ${ }^{11}$

\section{Cognitive impairment and depression}

Cognitive impairment often results from $\mathrm{MS},{ }^{12}$ and may make it difficult for the patient to follow correctly the prescribed treatment regimen. Current MS therapies require regular administration, and impaired memory function may reduce the likelihood of timely administration. Additionally, despite efforts to simplify the injection process through the design of delivery technology, cognitive dysfunction could also impair correct injection technique. However, the impact of cognitive impairment on adherence to MS therapy remains to be clarified in studies. Depression is common among patients with MS, and may negatively affect adherence. A study of patients with MS initiating IFN beta-1b therapy found that $41 \%$ of patients reported new or increased depression within 6 months of starting treatment. Eighty-six percent of patients who received psychotherapy or antidepressant treatment 
continued therapy, compared with $38 \%$ of patients who received no treatment for depression $(P=0.003){ }^{13}$

\section{Efficacy concerns}

Perceived lack of efficacy is one of the most commonly cited reasons for treatment discontinuation. ${ }^{8,11,14}$ The disease course of MS varies between patients, and while therapy is often effective, the individual patient may not fully understand the benefits of remaining on treatment. The effects of treatment may not become apparent immediately, which may in part explain the high discontinuation rates observed in the first few months of treatment. Additionally, the unpredictability of the disease course means it is impossible to predict how their MS would affect them were they not on treatment, so the true benefit of treatment in the individual patient is unclear. Some patients starting MS therapy tend to be overly optimistic about the benefits of therapy. Unrealistic expectations have been shown to be highly predictive of premature discontinuation. Therefore, it is important that patients' expectations are managed prior to treatment initiation. ${ }^{9,15}$ Importantly, if a patient does not adhere to the prescribed treatment regimen, they may experience poorer outcomes, lose faith in their treatment, and become even more likely to be poorly adherent.

\section{Adverse events}

AEs associated with MS therapy may also contribute to nonadherence to treatment regimens. The incidence of AEs associated with MS therapy tends to decrease the longer a patient is on therapy. Therefore, long-term adherence to treatment is more likely to be achieved if patients remain on treatment through the initial period when AEs can be particularly problematic. Management strategies to minimize the impact of AEs are therefore imperative to preserve adherence.

One of the most common AEs associated with IFN beta therapy is flu-like symptoms. ${ }^{16}$ These symptoms tend to appear early in the treatment course, then diminish in frequency and severity with increased time on treatment. For example, in the pivotal trial of sc IFN beta-1a, flu-like symptoms were reported by $69 \%$ of patients receiving IFN beta-1a over years 1 to 4 , but by only $12 \%$ after up to 8 years of follow up. ${ }^{17,18}$

Injection-site reactions (ISRs) are another commonly reported AE associated with MS therapies. The incidence and severity of such reactions may vary between treatments. ${ }^{8}$ Injection-site necrosis can occur with IFN beta treatment, and is very rarely seen with glatiramer acetate. ${ }^{19-21}$ However, glatiramer acetate injection can sometimes cause lipoatrophy at the application site, leading to, sometimes permanent, disfigurement. ${ }^{22,23}$ Correct injection technique and rotation of injection sites can help to avoid ISRs. ${ }^{24}$

\section{Inconvenience and needle phobia}

Aside from the AEs associated with MS therapies, some patients also find the process of regular self-injection burdensome, and adherence can be compromised as a result. Furthermore, physical disability and cognitive impairment resulting from MS can make self-injection and ability to comply with treatment regimens difficult. ${ }^{25}$ Needle phobia, which is experienced by up to $22 \%$ of the general population, can also be a significant barrier to self-administration of parenteral therapies among patients with MS. ${ }^{26}$ Studies in other therapy areas have shown that a complex regimen and frequent dosing schedule can be barriers to adherence. ${ }^{27}$ Currently, all first-line therapies for MS require parenteral administration weekly (in the case of im IFN beta-1a) or more frequently. In the case of glatiramer acetate, patients are required to inject daily. It may be speculated that patients with MS would be more adherent to drugs requiring less-frequent administration. Natalizumab is delivered via a monthly intravenous infusion. It could be argued that the dosing frequency and the fact that natalizumab is administered during a clinic visit could encourage adherence. Conversely, this route of administration may be considered inconvenient by some patients.

\section{Discontinuation patterns and consequences of poor adherence}

Discontinuation tends to occur earlier after treatment initiation if the reason for stopping therapy is AEs than when discontinuation is due to lack of efficacy. In a study of discontinuation patterns in patients receiving IFN beta, patients who stopped therapy as a result of AEs did so after a median period of 13 months on treatment, whereas those who discontinued as a result of treatment failure (defined as non-reduction in pre-treatment relapse rate and/or sustained increase of Expanded Disability Status Scale score of $\geq 1$ point) did so after a median period of 35 months $(P=0.0004$; Mann-Whitney test $) .^{28}$

In MS, it is currently unclear precisely what effect the degree to which patients adhere to therapy has on clinical or magnetic resonance imaging outcomes, but patients who do not adhere to therapy are unlikely to receive the full potential benefit of treatment, ${ }^{8}$ and therefore may be at increased risk of poorer outcomes. A study that investigated the relationship between the duration of gaps in MS treatment regimens and the 
incidence of severe MS relapses found that patients who had gaps in therapy lasting $\geq 90$ days had a nearly twofold greater probability of experiencing a severe relapse than patients with shorter gaps in therapy. ${ }^{29}$ This shows the importance of adherence to prescribed regimens for MS. Potential barriers to treatment adherence in MS are summarized in Figure 1. All of these issues can affect the patient's quality of life, whether they relate to features of the disease, or to the treatment itself. It may be speculated that poor overall quality of life may affect the individual patient's likelihood of adherence to therapy.

\section{Management strategies to enhance adherence}

Maximizing adherence to MS therapies to improve a patient's chance of gaining the full benefit from their treatment is an important therapeutic goal. Patient education is of paramount importance in achieving this, as a patient's commitment to a therapeutic regimen may well depend on their understanding of their condition, their need for treatment, and the potential benefits of treatment. ${ }^{15}$

As perceived lack of efficacy can be a barrier against adherence, patients need to have realistic expectations of their treatment, and again, information can enhance the likelihood of good adherence. A study that examined patients' expectations of treatment before beginning IFN beta therapy found that $57 \%$ of patients had unrealistic expectations about reduction in relapse rate. ${ }^{9}$ Although educational procedures significantly altered unrealistic expectations, $36 \%$ of patients still had unrealistic expectations of therapy after education. Of those patients who discontinued IFN beta therapy, $64 \%$ had unrealistically optimistic post-education expectations of treatment. ${ }^{9}$

Patients should be informed of therapeutic options, the potential benefits and risks of each treatment and the importance of adhering to their given treatment regimen. Allowing patients to take an active role in treatment decisions may make them feel empowered, which, in turn, could enhance their motivation to remain adherent. Patients also benefit from receiving information about potential side-effects, and how these can be managed. ${ }^{15}$

AEs may occur with MS therapies, but they can be managed so as to minimize the impact on the patient's life. As all DMDs for MS require frequent injections, ISRs and pain may be experienced. Suitable injection technique can minimize these events and thus enhance adherence. Appropriate injection procedures include those outlines below.

- Refrigerated medication should be warmed to room temperature before administration.

- Hands should be washed thoroughly prior to injection.

- The injection site should be thoroughly cleansed but completely dry before the injection.

- Ice should not be applied to the skin before injection, but may be used afterwards.

- The needle should be inserted perpendicularly to the skin and completely penetrate the skin.

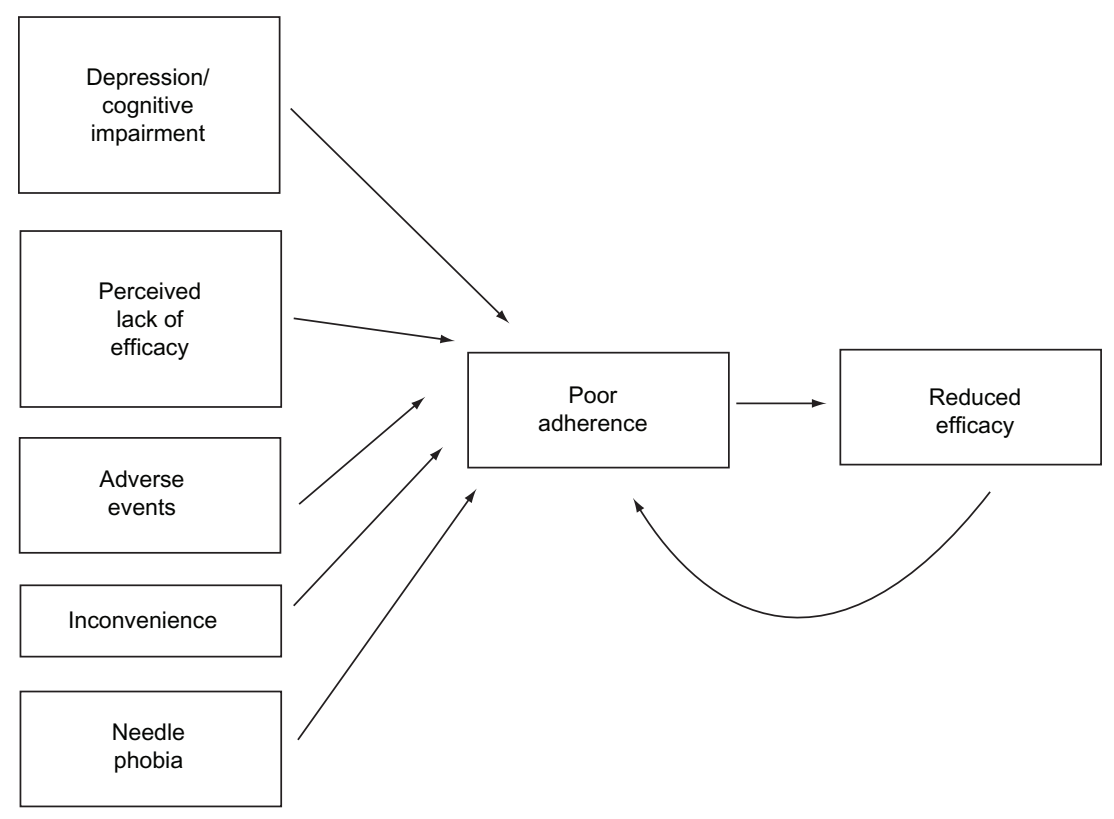

Figure I Factors leading to poor adherence to multiple sclerosis therapy. 
- For im injections, shorter needles should be used for patients with less subcutaneous fat.

- The patient should avoid smoking.

- Auto-injector use is recommended.

- Rotation of injection sites is vital to minimize reactions due to repeated, frequent injections.

- The use of topical steroid preparations is not recommended.

The use of auto-injector devices to administer DMDs has been shown to reduce the incidence of ISRs compared with manual injection. ${ }^{30}$ These devices are also convenient to use, and may be particularly beneficial for patients with poor manual dexterity. ${ }^{31}$ As needle phobia can be a barrier to adherence to injectable therapies ${ }^{26}$ a device in which the needle is hidden from view may have the additional benefit of reducing anxiety and thus improving adherence.

Many patients treated with IFN beta experience flu-like symptoms, particularly during the few months after treatment is started. Dose titration at initiation of IFN beta treatment is commonly employed to minimize the incidence of flu-like symptoms. A useful scheme for the titration of IFN beta treatment is to begin with $25 \%$ of the full dose for the first week, $50 \%$ in the second, and if this is well tolerated, the full dose is given from the third week onwards. ${ }^{16}$ Concomitant nonsteroidal anti-inflammatory drug (NSAID) treatment, either prophylactically or as required, can also help to reduce these symptoms. ${ }^{16}$ Low doses of corticosteroids may be administered to patients who do not respond satisfactorily to NSAIDs for flu-like symptoms. A randomized study compared the efficacy of corticosteroids, ibuprofen, and acetaminophen for the control of IFN beta-related flu-like symptoms. The three treatments showed a similar degree of efficacy on flulike symptoms, although flu-like symptoms immediately following injection were less severe in patients treated with ibuprofen. ${ }^{32}$ Another technique for the management of flulike symptoms is for patients to administer their therapy in the evening, meaning that the majority of acute symptoms occur while they are asleep. ${ }^{16}$

Adherence to MS therapy can be enhanced by providing the patient with a support network. Often, the MS nurse is well placed to co-ordinate the support network, being the central point of contact with the patient once therapy has been initiated. MS nurses can provide the patient with information on available support services offered by the clinic or in the community. Many patients find that self-help groups can provide valuable support and information. Additionally, the MS nurse can advise the patient on the management of symptoms, side-effects, and co-morbidities.
In addition to the care provided by the physician and nurse, treatment, information, and support from a wider, multidisciplinary team can enhance further the patient's adherence to therapy. ${ }^{33}$ The patient and their family and friends are central in this care model, with support from the family practitioner, physiotherapist, neuropsychologist, and MS societies forming valuable relationships with the patient. Many patients report that how they are treated by their care team influences their likelihood of following medical recommendations. ${ }^{33}$ One study of adherence to IFN beta-1b in 939 patients with SPMS found that the highest rates of adherence were achieved in clinics where empathetic and less formal relationships between patients and caregivers were encouraged. ${ }^{34}$ Effective and sensitive working relationships between the patient and their support team are an important part of the patient's care. As the disease course of MS is unpredictable, and the patient's attitudes and behavior patterns can be changeable, encouraging adherence is a complex issue. The support team needs to be aware of the potential barriers to adherence and sensitive to the patient's state of mind in order to support the patient with the goal of maintaining adherence. ${ }^{35}$

The formulation of MS drugs can influence their tolerability, and formulation adjustments may serve to improve tolerability and so enhance adherence. For example, IFN beta-1a for sc injection has been re-formulated, produced without fetal bovine serum and without human serum albumin as an excipient. A recent 2-year study ${ }^{36}$ compared data on the tolerability and immunogenicity of patients treated with the new formulation of sc IFN beta-1a $(n=260)$ with historical data on patients treated with the previous formulation of sc IFN beta-1a in the EVIDENCE $(n=339)$ and REGARD $(\mathrm{n}=381)$ trials. The incidence of ISRs in patients receiving the new formulation was $31 \%$, almost three times lower than in the EVIDENCE study (86\%), and lower than in the REGARD study (41\%). Levels of immunogenicity were lower with the new formulation than in the historical cohort, with apparent comparable efficacy. However, it remains to be seen whether these improvements in tolerability and immunogenicity will translate into higher adherence rates. A study that assessed the immunogenicity and safety of a human serum albumin-free formulation of im IFN beta-1a found the tolerability profile of the human serum albumin-free formulation similar to that of the original formulation. ${ }^{37}$

\section{Future directions for the enhancement of adherence in MS}

There are several strategies being explored that may prove to enhance adherence to MS therapies. These include advances 
in delivery technology, improved patient education and support programs and alternative routes of administration. Perhaps the most important advance in MS treatment that is anticipated to significantly improve adherence to long-term treatment will be the availability of orally administered drugs. In terms of adherence, oral drugs have a potential advantage over injected therapies in that needle phobia and injection-related AEs will not be an issue, making treatment available to patients with MS who are unable, or unwilling, to receive regular injections. Nonparenteral routes of drug administration can also be expected to enhance adherence. ${ }^{1}$ In other therapy areas, such as oncology and diabetes, patients prefer receiving their medication in the form of tablets or an inhaled preparation, rather than as injections. ${ }^{38-40}$ Additionally, oral or inhaled medications are associated with heightened levels of patient satisfaction with their treatment. ${ }^{38,41}$ Therefore, with the more convenient administration route, oral MS therapies may be expected to improve rates of adherence compared with those found with injected drugs.

Although the development of new oral agents for the treatment of MS is an important step in improving adherence to MS therapy, oral administration may not entirely solve the problem of poor adherence. The example of osteoporosis treatment clearly shows that frequency of dosing can greatly influence the adherence to oral therapies. Studies show that persistence with weekly oral bisphosphonate therapy is substantially greater than with a daily regimen, although still not optimal. Additionally, patient surveys show that the majority of patients prefer a weekly regimen to daily, with a once-monthly regimen being the most popular. ${ }^{42}$ Studies in other therapy areas have also shown that simpler ${ }^{43,44}$ and less frequent $t^{45,46}$ dosing produces greater adherence than more frequent administration.
Several oral agents for the treatment of MS are currently being studied in Phase III trials (Table 1). Laquinimod, a derivative of linomide, alters dendritic cell responses and promotes a shift to Th2 immunity. ${ }^{47}$ BG-12 is a second-generation fumaric acid derivative, which has shown promising results on MRI measures of MS in Phase II studies. ${ }^{48}$ Fingolimod (FTY720) is a sphingosine1 -phosphate agonist that was originally investigated for the prevention of renal transplant rejection. It is an immunosuppressive agent that induces lymphopenia by sequestering lymphocytes into secondary lymph nodes. Via this mechanism it prevents $T$ cells from crossing the blood-brain barrier and invading the CNS. Fingolimod preferentially depletes B cells and may have vasoprotective properties and neuroprotective effects. Phase II trials of fingolimod in patients with MS showed efficacy in MRI and clinical measures. ${ }^{49}$ Preliminary results of a Phase III study indicate that the efficacy of fingolimod is superior to that of im IFN beta-1a for relapse rate..$^{50}$ Leflunomide is used in the treatment of rheumatoid arthritis. Its active metabolite, teriflunomide, reduced the number of MRI lesions in patients with MS in Phase II trials. It causes the selective depletion of $\mathrm{B}$ and $\mathrm{T}$ cells by inhibiting the synthesis of pyrimidine nucleotides. ${ }^{51}$ Cladribine is a small molecule, which acts as a prodrug: a deoxyadenosine analogue immunomodulator that is resistant to deamination by the enzyme adenosine deaminase. Activation of cladribine in specific cell types results in preferential reduction of lymphocyte B and T subtypes, ${ }^{52,53}$ both of which are involved in MS pathogenesis, ${ }^{54,55}$ with relatively minor effects on other hematological and immune cell types. ${ }^{52,56-58}$ Cladribine tablets therapy was developed following encouraging clinical trial experience with parenteral cladribine in MS. ${ }^{52,56,59}$ The sustained

Table I Oral agents currently in Phase III trials for multiple sclerosis

\begin{tabular}{|c|c|c|c|c|}
\hline Agent & Molecule type & Therapeutic target & Current/previous use & Expected dosing regimen \\
\hline Fingolimod & $\begin{array}{l}\text { Partial sphingosine- } \\
\text { I-phosphate receptor agonist }\end{array}$ & Lymphocyte trafficking & $\begin{array}{l}\text { Renal transplantation } \\
\text { (failed Phase III trials) }\end{array}$ & 5.0 or $1.25 \mathrm{mg}$ daily \\
\hline Laquinimod & $\begin{array}{l}\text { Derivative of linomide } \\
\text { (roquinimex) }\end{array}$ & Prevention of T-cell activation & $\begin{array}{l}\text { Oncology (antiangiogenic } \\
\text { agent) }\end{array}$ & $0.6 \mathrm{mg}$ daily \\
\hline BG- 12 & Fumaric acid derivative & Prevention of T-cell activation & $\begin{array}{l}\text { Psoriasis (approved in } \\
\text { Germany) }\end{array}$ & 720 mg daily \\
\hline Teriflunomide & $\begin{array}{l}\text { Active metabolite of } \\
\text { leflunomide }\end{array}$ & $\begin{array}{l}\text { Lymphocyte antiproliferation } \\
\text { agent }\end{array}$ & Rheumatoid arthritis & 7.0 or $14.0 \mathrm{mg}$ daily \\
\hline Cladribine & $\begin{array}{l}\text { Purine nucleoside analog } \\
\text { pro-drug }\end{array}$ & $\begin{array}{l}\text { Preferential reduction of } \\
T \text { and } B \text { lymphocyte subtypes }\end{array}$ & $\begin{array}{l}\text { Hairy cell leukemia and } \\
\text { lymphoma }\end{array}$ & $\begin{array}{l}\text { Short-course annual dosing } \\
\text { regimen }(3.5 \mathrm{mg} / \mathrm{kg} \text { or } \\
5.25 \mathrm{mg} / \mathrm{kg} \text { over } 96 \text { weeks })\end{array}$ \\
\hline
\end{tabular}


effects on $\mathrm{T}$ and $\mathrm{B}$ cells has allowed for the development of cladribine tablets using a short-course annual dosing regimen. This may mean that patients need to take tablets for 10 or 20 days per year. Cladribine tablets recently became the first orally administered investigational treatment for MS to complete a 2-year Phase III pivotal study in which it demonstrated rapid and significant improvements in clinical outcome measures, including reductions in relapse rates and the risk of developing 3-month sustained disability progression relative to placebo in patients with relapsing-remitting MS. ${ }^{60-62}$

Should one or more of these oral therapies in development be approved for the treatment of MS, it may be speculated that their benefits would lead to higher levels of treatment adherence currently seen with parenteral treatments. While a change in administration route is unlikely to completely solve the problem of poor adherence, the advent of oral therapies represents a significant milestone in the care of patients with MS.

\section{Conclusions}

Adherence to treatment regimens is essential for patients to gain the full benefit of their therapies. ${ }^{1}$ Although the impact of non-adherence to MS therapies has not been widely assessed, it is reasonable to assume that poor adherence to MS drugs results in poorer outcomes. It has been shown that long interruptions in MS therapy confer a higher risk of severe relapse. ${ }^{29}$ As with other chronic diseases such as cancer and diabetes, nonadherence and poor adherence to therapy are common in MS, and improving adherence should be recognized as an important treatment goal in its own right. Many factors can cause patients to discontinue treatment, including treatment-related AEs and patient perception of lack of efficacy. Where possible, these should be addressed through patient education and support, and strategies to maximize drug tolerability to improve adherence. Appropriate measures to enhance adherence are summarized below.

- Adherence must be considered an important modifier of the efficacy of long-term treatment.

- The management of patients' expectations should be central in the process of treatment of patients with MS.

- Patients should be trained in appropriate injection technique (such as rotation, self-injection).

- Patients must be informed of the potential side-effects and on the correct management of the latter.

- Specific work must be done with non-adherent patients, and the possibility of switching to a different therapy, if appropriate, should be discussed.
Oral therapies currently in development also have the potential to improve adherence: the absence of ISRs and ease of administration may make these treatments more acceptable to patients, particularly if the tablet burden is low.

While suboptimal adherence to MS therapies remains a problem, adherence can be enhanced by various strategies. Future developments in drug and administration technology may be expected to further improve adherence, and therefore patient outcomes.

\section{Acknowledgments}

The author takes full responsibility for the content of the paper but thank Steve Smith, Caudex Medical (supported by Merck Serono S.A. - Geneva, Switzerland, an affiliate of Merck KGaA, Darmstadt, Germany), for his assistance in preparing the initial draft.

\section{Disclosures}

The author has received financial support for research activities from the University of Catania and has also received fees from Merck Serono S.A. - Geneva, Switzerland, an affiliate of Merck KGaA, Darmstadt, Germany and SanofiAventis, as well as fees from Bayer Schering Pharma for speaking services. The author takes full responsibility for the data, the analyses and the interpretation, and the conduct of the research; had full access to the data; and has the right to publish any and all data, separate and apart from the attitudes of the sponsor.

\section{References}

1. World Health Org. Adherence to long-term therapies. URL: http://www who.int/chp/knowledge/publications/adherence_report/en/index.html. Accessed Feb 26, 2007.

2. Partridge AH, Avorn J, Wang PS, Winer EP. Adherence to therapy with oral antineoplastic agents. J Natl Cancer Inst. 2002;94:652-6561.

3. Lee WC, Balu S, Cobden D, Joshi AV, Pashos CL. Prevalence and economic consequences of medication adherence in diabetes: a systematic literature review. Manag Care Interface. 2006;19:31-41.

4. Who gets MS? URL: http://www.nationalmssociety.org/about-multiplesclerosis/who-gets-ms/index.aspx. Accessed May 21, 2009.

5. Weinshenker BG, Bass B, Rice GP, Noseworthy J, Carriere W, Baskerville J, et al. The natural history of multiple sclerosis: a geographically based study. 1. Clinical course and disability. Brain. 1989;112 (Pt 1):133-146.

6. Gonsette RE. Mitoxantrone immunotherapy in multiple sclerosis. Mult Scler. 1996;1:329-332.

7. Natalizumab SPC. URL: http://emc.medicines.org.uk/emc/assets/c/ html/displaydoc.asp?documentid=18447. Accessed Nov 29, 2007.

8. Tremlett HL, Oger J. Interrupted therapy: stopping and switching of the beta-interferons prescribed for MS. Neurology. 2003;61:551-554.

9. Mohr DC, Goodkin DE, Likosky W, Gatto N, Neilley LK, Griffin C, et al. Therapeutic expectations of patients with multiple sclerosis upon initiating interferon beta-1b: relationship to adherence to treatment. Mult Scler. 1996;2:222-226.

10. Portaccio E, Zipoli V, Siracusa G, Sorbi S, Amato MP. Long-term adherence to interferon beta therapy in relapsing-remitting multiple sclerosis. Eur Neurol. 2008;59:131-135. 
11. Rio J, Porcel J, Tellez N, Sanchez-Betancourt A, Tintore M, Arevalo MJ, et al. Factors related with treatment adherence to interferon beta and glatiramer acetate therapy in multiple sclerosis. Mult Scler. 2005; 11:306-309.

12. Rao SM, Leo GJ, Bernardin L, Unverzagt F. Cognitive dysfunction in multiple sclerosis. I. Frequency, patterns, and prediction. Neurology. 1991;41:685-691.

13. Mohr DC, Goodkin DE, Likosky W, Gatto N, Baumann KA, Rudick RA. Treatment of depression improves adherence to interferon beta-1b therapy for multiple sclerosis. Arch Neurol. 1997;54: 531-533.

14. Clerico M, Barbero P, Contessa G, Ferrero C, Durelli L. Adherence to interferon-beta treatment and results of therapy switching. J Neurol Sci. 2007;259:104-108.

15. Frohman E, Phillips T, Kokel K, Van Pelt J, O’Leary S, Gross S, et al. Disease-modifying therapy in multiple sclerosis: strategies for optimizing management. Neurologist. 2002;8:227-236.

16. Bayas A, Rieckmann P. Managing the adverse effects of interferon beta therapy in multiple sclerosis. Drug Saf. 2000;22:149-159.

17. PRISMS Study Group, University of British Columbia MS/MRI Analysis Group. PRISMS-4: long-term efficacy of interferon-beta-1a in relapsing MS. Neurology. 2001;56:1628-1636.

18. Kappos L, Traboulsee A, Constantinescu C, Eralinna JP, Forrestal F, Jongen $\mathrm{P}$, et al. Long-term subcutaneous interferon beta-1a therapy in patients with relapsing-remitting MS. Neurology. 2006;67: 944-953.

19. Avonex SPC. URL: http://emc.medicines.org.uk/emc/assets/c/html/ displaydoc.asp?documentid=257. Accessed Nov 29, 2007.

20. Betaferon SPC. URL: http://emc.medicines.org.uk/emc/assets/c/html/ displaydoc.asp?documentid=1809. Accessed Nov 29, 2007.

21. Rebif SPC. URL: http://emc.medicines.org.uk/emc/assets/c/html/ displaydoc. .asp?documentid=18578. Accessed Nov 29, 2007.

22. Edgar CM, Brunet DG, Fenton P, McBride EV, Green P. Lipoatrophy in patients with multiple sclerosis on glatiramer acetate. Can J Neurol Sci. 2004;31:58-63.

23. Soos N, Shakery K, Mrowietz U. Localized panniculitis and subsequent lipoatrophy with subcutaneous glatiramer acetate (Copaxone) injection for the treatment of multiple sclerosis. Am J Clin Dermatol. 2004;5:357-359.

24. Walther EU, Hohlfeld R. Multiple sclerosis: side effects of interferon beta therapy and their management. Neurology. 1999;53:1622-1627.

25. Lesaux J, Jadback G, Harraghy CE. Improving the convenience of home-based interferon beta-1a therapy for multiple sclerosis. J Neurosci Nurs. 1999;31:174-179.

26. Cox D, Stone J. Managing self-injection difficulties in patients with relapsing-remitting multiple sclerosis. $J$ Neurosci Nurs. 2006;38: 167-171.

27. Richter A, Anton SE, Koch P, Dennett SL. The impact of reducing dose frequency on health outcomes. Clin Ther. 2003;25:2307-2335.

28. O'Rourke KE, Hutchinson M. Stopping beta-interferon therapy in multiple sclerosis: an analysis of stopping patterns. Mult Scler. 2005; 11:46-50.

29. Al-Sabbagh A, Bennet R, Kozma C, Dickson M, Meletiche D. Medication gaps in disease-modifying therapy for multiple sclerosis are associated with an increased risk of relapse: findings from a national managed care database. J Neurol. 2008;255(Suppl 2):S79.

30. Mikol D, Lopez-Bresnahan M, Taraskiewicz S, Chang P, Rangnow J. A randomized, multicentre, open-label, parallel-group trial of the tolerability of interferon beta-1a (Rebif) administered by autoinjection or manual injection in relapsing-remitting multiple sclerosis. Mult Scler. 2005; 11:585-591.

31. Cramer JA, Cuffel BJ, Divan V, Al-Sabbagh A, Glassman M. Patient satisfaction with an injection device for multiple sclerosis treatment. Acta Neurol Scand. 2006;113:156-162.

32. Rio J, Nos C, Bonaventura I, Arroyo R, Genis D, Sureda B, et al. Corticosteroids, ibuprofen, and acetaminophen for IFNbeta-1a flu symptoms in MS: a randomized trial. Neurology. 2004;63:525-528.
33. Denis L, Namey M, Costello K, Frenette J, Gagnon N, Harris C, et al. Long-term treatment optimization in individuals with multiple sclerosis using disease-modifying therapies: a nursing approach. J Neurosci Nurs. 2004;36:10-22.

34. Mohr DC, Goodkin DE, Masuoka L, Dick LP, Russo D, Eckhardt J, et al. Treatment adherence and patient retention in the first year of a Phase-III clinical trial for the treatment of multiple sclerosis. Mult Scler. 1999;5:192-197.

35. Glanz B, Holland C, Gauthier S, Amunwa E, Liptak Z, Houtchens M, et al. Cognitive dysfunction in patients with clinically isolated syndromes or newly diagnosed multiple sclerosis. Mult Scler. 2007;13:1004-1010.

36. Giovannoni G, Barbarash O, Casset-Semanaz F, King J, Metz L, Pardo G, et al. Safety and immunogenicity of a new formulation of interferon beta-1a (Rebif New Formulation) in a phase IIIb study in patients with relapsing multiple sclerosis: 96-week results. Mult Scler. 2009;15:219-228.

37. Phillips JT, Rice G, Frohman E, Vande Gaer L, Scott T, Haas J, et al. A multicenter, open-label, phase II study of the immunogenicity and safety of a new prefilled syringe (liquid) formulation of Avonex in patients with multiple sclerosis. Clin Ther. 2004;26:511-521.

38. Bellary S, Barnett AH. Inhaled insulin (Exubera): Combining efficacy and convenience. Diab Vasc Dis Res. 2006;3:179-185.

39. Fallowfield L, Atkins L, Catt S, Cox A, Coxon C, Langridge C, et al. Patients' preference for administration of endocrine treatments by injection or tablets: results from a study of women with breast cancer. Ann Oncol. 2006;17:205-210.

40. Liu G, Franssen E, Fitch MI, Warner E. Patient preferences for oral versus intravenous palliative chemotherapy. J Clin Oncol. 1997;15:110-115.

41. Atkinson MJ, Sinha A, Hass SL, Colman SS, Kumar RN, Brod M, et al. Validation of a general measure of treatment satisfaction, the Treatment Satisfaction Questionnaire for Medication (TSQM), using a national panel study of chronic disease. Health Qual Life Outcomes. 2004;2:12:12-24.

42. Reginster JY, Rabenda V, Neuprez A. Adherence, patient preference and dosing frequency: understanding the relationship. Bone. 2006;38:S2-S6.

43. Clotet B, Carmena J, Pulido F, Luque I, Rodriguez-Alcantara F. Adherence, quality of life, and general satisfaction with co-formulated zidovudine, lamivudine, and abacavir on antiretroviral-experienced patients. HIV Clin Trials. 2004;5:33-39.

44. Sleight $P$, Pouleur H, Zannad F. Benefits, challenges, and registerability of the polypill. Eur Heart J. 2006;27:1651-1656.

45. Rau JL. Determinants of patient adherence to an aerosol regimen. Respir Care. 2005;50:1346-1356.

46. Kruk ME, Schwalbe N. The relation between intermittent dosing and adherence: preliminary insights. Clin Ther. 2006;28:1989-1995.

47. Yang JS, Xu LY, Xiao BG, Hedlund G, Link H. Laquinimod (ABR215062) suppresses the development of experimental autoimmune encephalomyelitis, modulates the Th1/Th2 balance and induces the Th3 cytokine TGF-beta in Lewis rats. J Neuroimmunol. 2004;156:3-9.

48. Kappos L, Miller D, MacManus DG, Gold R, Havrdova E, Limmroth V, et al. BG00012, a novel oral fumarate, is effective in patients with relapsingremitting multiple sclerosis. Mult Scler. 2006;12(Suppl 1):P325.

49. Kappos L, Antel J, Comi G, Montalban X, O’Connor P, Polman CH, et al. Oral fingolimod (FTY720) for relapsing multiple sclerosis. $N$ Engl J Med. 2006;355:1124-1140.

50. First Phase III results for FTY720, a novel oral therapy for MS, show superior efficacy compared to interferon beta-1a. URL: http://www.pharma. us.novartis.com/newsroom/press-release.jsp?PRID=2179\&usertrack. filter_applied $=$ true $\&$ NovaId $=1178761806479528335$. Accessed Feb 10, 2009.

51. Zeyda M, Poglitsch M, Geyeregger R, Smolen JS, Zlabinger GJ, Horl WH, et al. Disruption of the interaction of T cells with antigenpresenting cells by the active leflunomide metabolite teriflunomide: involvement of impaired integrin activation and immunologic synapse formation. Arthritis Rheum. 2005;52:2730-2739.

52. Beutler E, Sipe JC, Romine JS, Koziol JA, McMillan R, Zyroff J. The treatment of chronic progressive multiple sclerosis with cladribine. Proc Natl Acad Sci U S A. 1996;93:1716-1720. 
53. Soelberg-Sorensen P, Comi G, Cook S, Giovannoni G, Rammohan K, Rieckmann P, et al. Haematological profiles in patients treated with cladribine tablets for relapsing-remitting multiple sclerosis (RRMS): results from the CLARITY study, a 96 week, phase III, double-blind, placebo-controlled trial. J Neurol. 2009;256:S127-S128.

54. Chitnis T. The role of CD4 T cells in the pathogenesis of multiple sclerosis. Int Rev Neurobiol. 2007;79:43-72.

55. Babbe H, Roers A, Waisman A, Lassmann H, Goebels N, Hohlfeld R, et al. Clonal expansions of CD8(+) T cells dominate the $\mathrm{T}$ cell infiltrate in active multiple sclerosis lesions as shown by micromanipulation and single cell polymerase chain reaction. J Exp Med. 2000;192:393-404.

56. Rice GP, Filippi M, Comi G. Cladribine and progressive MS: clinical and MRI outcomes of a multicenter controlled trial. Cladribine MRI Study Group. Neurology. 2000;54:1145-1155.

57. Grieb P, Kamienowski J, Janisz M, Kuœnierczyk P, Kawiak J, Hoser G, et al. Hematological effects of intermittent 2-hour infusions of cladribine in multiple sclerosis patients: a comparison of 2 dosage patterns. Int $J$ Hematol. 2001;74:421-427.

58. Soelberg-Sorensen P, Comi G, Cook S, Giovannoni G, Rammohan K, Rieckmann P, et al. Effects of cladribine tablets on haematological profiles in patients with relapsing-remitting multiple sclerosis (RRMS) in the 96 week, phase III, double blind, placebo-controlled CLARITY study. Mult Scler. 2009;15:S137.
59. Romine JS, Sipe JC, Koziol JA, Zyroff J, Beutler E. A double-blind, placebo-controlled, randomized trial of cladribine in relapsing-remitting multiple sclerosis. Proc Assoc Am Physicians. 1999;111:35-44.

60. Merck Serono's Oral Investigational Treatment Cladribine Tablets for Multiple Sclerosis Significantly Reduced Relapse Rate in Two-Year Phase III Pivotal Trial. URL: http://www.merckserono.com/corp. merckserono/en/images/20090123_en_tcm112_34916.pdf. Accessed Feb 10, 2009.

61. Giovannoni G, Comi G, Cook S, Rammohan K, Rieckmann P, Sorensen $\mathrm{P}$, et al. Clinical outcomes with cladribine tablets in the 96-week, phase III, double-blind, placebo-controlled CLARITY study in patients with relapsing-remitting multiple sclerosis. Mult Scler. 2009;15:S136-S137.

62. Vermersch P, Comi G, Cook S, Giovannoni G, Rammohan K, Rieckmann P, et al. Early onset of effect of treatment with cladribine tablets for relapsing-remitting multiple sclerosis in the 96-week, phase III, double-blind, placebo-controlled CLARITY study. Mult Scler. 2009; 15:S249.
Patient Preference and Adherence

\section{Publish your work in this journal}

Patient Preference and Adherence is an international, peer-reviewed, open access journal that focusing on the growing importance of patient preference and adherence throughout the therapeutic continuum. Patient satisfaction, acceptability, quality of life, compliance, persistence and their role in developing new therapeutic modalities and compounds to

\section{Dovepress}

optimize clinical outcomes for existing disease states are major areas of interest. This journal has been accepted for indexing on PubMed Central. The manuscript management system is completely online and includes a very quick and fair peer-review system. Visit http://www.dovepress.com/ testimonials.php to read real quotes from published authors.

Submit your manuscript here: http://www.dovepress.com/patient-preference-and-adherence-journal 